\title{
Facilitated transport of titanium dioxide nanoparticles by humic substances in saturated porous media under acidic conditions
}

\author{
Ruichang Zhang $\cdot$ Haibo Zhang $\cdot$ Chen Tu $\cdot$ \\ Xuefeng $\mathrm{Hu} \cdot$ Lianzhen Li $\cdot$ Yongming Luo • \\ Peter Christie
}

Received: 15 December 2014/Accepted: 18 March 2015/Published online: 1 April 2015

(C) Springer Science+Business Media Dordrecht 2015

\begin{abstract}
The transport behavior of titanium dioxide nanoparticles $\left(\mathrm{TiO}_{2} \mathrm{NPs}, 30 \mathrm{~nm}\right.$ in diameter) was studied in well-defined porous media composed of clean quartz sand over a range of solution chemistry under acidic conditions. Transport of $\mathrm{TiO}_{2}$ NPs was dramatically enhanced by humic substances (HS) at acidic $\mathrm{pH}$ (4.0, 5.0 and 6.0), even at a low HS concentration of $0.5 \mathrm{mg} \mathrm{L}^{-1}$. Facilitated transport of $\mathrm{TiO}_{2}$ NPs was likely attributable to the increased stability of $\mathrm{TiO}_{2}$ NPs and repulsive interaction between $\mathrm{TiO}_{2}$ NPs and quartz sands due to the adsorbed HS. The mobility of $\mathrm{TiO}_{2} \mathrm{NPs}$ was also increased with increasing $\mathrm{pH}$ from 4.0 to 6.0. Although transport of $\mathrm{TiO}_{2}$ NPs was insensitive to low ionic strength, it was
\end{abstract}

Electronic supplementary material The online version of this article (doi:10.1007/s11051-015-2972-y) contains supplementary material, which is available to authorized users.

R. Zhang · Y. Luo · P. Christie

Key Laboratory of Soil Environment and Pollution Remediation, Institute of Soil Science, Chinese Academy of Sciences, Nanjing 210008, China

R. Zhang

University of Chinese Academy of Sciences, Beijing, China

H. Zhang $\cdot$ C. Tu $\cdot$ X. Hu $\cdot$ L. Li $\cdot$ Y. Luo $(\bowtie)$

Key Laboratory of Coastal Environmental Processes and Ecological Remediation, Yantai Institute of Coastal Zone Research, Chinese Academy of Sciences, Yantai 264003, China

e-mail:ymluo@yic.ac.cn significantly inhibited by high concentrations of $\mathrm{NaCl}$ and $\mathrm{CaCl}_{2}$. In addition, calculated Derjaguin-LandauVerwey-Overbeek (DLVO) interaction energy indicated that high energy barriers were responsible for the high mobility of $\mathrm{TiO}_{2} \mathrm{NPs}$, while the secondary energy minimum could play an important role in the retention of $\mathrm{TiO}_{2} \mathrm{NPs}$ at $100 \mathrm{mmol} \mathrm{L}^{-1} \mathrm{NaCl}$. Straining and gravitational settlement of larger $\mathrm{TiO}_{2} \mathrm{NPs}$ aggregates at $1 \mathrm{mg} \mathrm{L}^{-1} \mathrm{HS}$, pH 5.0, and $2 \mathrm{mmol} \mathrm{L}{ }^{-1} \mathrm{CaCl}_{2}$ could be responsible for the significant retention even in the presence of high energy barriers. Moreover, more favorable interaction between approaching $\mathrm{TiO}_{2} \mathrm{NPs}$ and $\mathrm{TiO}_{2} \mathrm{NPs}$ that had been already deposited on the collector resulted in a ripening-shape breakthrough curve at $2 \mathrm{mmol} \mathrm{L}{ }^{-1} \mathrm{CaCl}_{2}$. Overall, a combination of mechanisms including DLVO-type force, straining, and physical filtration was involved in the retention of $\mathrm{TiO}_{2}$ NPs over the range of solution chemistry examined in this study.

Keywords Titanium dioxide nanoparticles . Facilitated transport - Humic substances . Mechanisms · Aggregation - Straining · Transport phenomena

\section{Introduction}

Titanium dioxide nanoparticles $\left(\mathrm{TiO}_{2} \mathrm{NPs}\right)$ are one of the most extensively used types of metal oxide nanomaterials in a variety of commercial products 
including cosmetics, coatings, paints, pigments, textiles, and photocatalysts (Chen and Mao 2007; Keller et al. 2013). Given that, $\mathrm{TiO}_{2} \mathrm{NPs}$ are inevitably released into the natural environment, especially in waste disposal sites or by accidental leakage events during manufacturing and transportation processes (Gottschalk et al. 2009; Lin et al. 2010). A modeling study showed that $\mathrm{TiO}_{2}$ NPs were expected to have the highest concentrations out of engineered materials $\left(\mathrm{TiO}_{2}, \mathrm{ZnO}, \mathrm{Ag}, \mathrm{CNTs}\right.$, and fullerenes) in all environmental compartments in the United States, Switzerland, and Europe (Gottschalk et al. 2009; Keller et al. 2013). In addition, a number of laboratory studies have noted adverse effects of $\mathrm{TiO}_{2} \mathrm{NPs}$ on organisms including animals (Menard et al. 2011), plants (Du et al. 2011), and microorganisms (Ge et al. 2011) in environmental media. And recent studies suggested that $\mathrm{TO}_{2}$ NPs might facilitate the transport of coexisting pollutants in soils (Fang et al. 2011), and act as a carrier for $\mathrm{Cd}$ bioaccumulation in the ciliate Tetrahymena thermophila (Yang et al. 2014).

Once released into the environment, the potential exposure pathways and bioavailability of $\mathrm{TiO}_{2} \mathrm{NPs}$ will be strongly influenced by their stability and transport behaviors. Quantification of the mobility of engineered nanoparticles in hydrologic pathways from point of release to human or ecological receptors is therefore essential for assessing their environmental exposures (Bouchard et al. 2013). A substantial amount of work on transport and deposition behaviors of $\mathrm{TiO}_{2} \mathrm{NPs}$ has been conducted in various aqueous environmental conditions using well-controlled porous media packing columns. These investigations have provided insights into the influence of environmental conditions, such as $\mathrm{pH}$, ionic strength, natural organic matter, and surfactants on the stability and mobility of $\mathrm{TiO}_{2}$ NPs (Chen et al. 2011, 2012; Chowdhury et al. 2011; Fang et al. 2013; Shih et al. 2012; Solovitch et al. 2010; Wang et al. 2012). pH is a key factor affecting the electrokinetic properties and transport of $\mathrm{TiO}_{2} \mathrm{NPs}$ in porous media. The point of zero charge (PZC) of $\mathrm{TiO}_{2}$ NPs usually falls within the range 4.4-6.2 (Chen et al. 2012; Dietrich et al. 2012; Loosli et al. 2013; Petosa et al. 2012), and the mobility of uncoated $\mathrm{TiO}_{2} \mathrm{NPs}$ would therefore be enhanced in alkaline conditions because of the unfavorable electrostatic repulsion between the particles and negatively charged collector (Fang et al. 2013; Solovitch et al. 2010; Wang et al. 2012). In contrast, when $\mathrm{pH}$ approached to the PZC, the concurrence of aggregation and limited mobility of bare $\mathrm{TiO}_{2}$ NPs was observed in the porous media (Chowdhury et al. 2011; Godinez and Darnault 2011; Solovitch et al. 2010). pH of surface water and subsurface water is generally in the range of 5.0-9.0; however, some of environmental media in vast tropical and subtropical areas exist in acidic conditions. Despite the large number of publications on the aggregation and transport of $\mathrm{TiO}_{2} \mathrm{NPs}$, there were very few systematic studies focusing on its stability and transport behavior under acidic conditions in porous media and few results available showed some discrepancy. The limited studies conducted showed inconsistent results, and both retention and mobility of $\mathrm{TiO}_{2}$ NPs in porous media have been reported under acidic conditions. Fang et al. (2013) found that favorable attachment condition at $\mathrm{pH} 2.6$ resulted in complete retention of $\mathrm{TiO}_{2}$ NPs in both saturated and unsaturated porous columns. However, Chowdhury et al. (2011) demonstrated that a significant portion of $\mathrm{TiO}_{2}$ NPs could be eluted from porous columns at $\mathrm{pH} 5.0$, which might be attributed to the observed smaller aggregate size and blocking effect even with electrostatically favorable interaction between collector and $\mathrm{TiO}_{2} \mathrm{NPs}$.

Natural organic matter (NOM) which is ubiquitously distributed in aquatic environments and soils is another key factor governing the environmental transport and fate of nanoparticles (Zhou et al. 2011). Adsorption of NOM onto the surface of $\mathrm{TiO}_{2}$ NPs significantly altered the physicochemical characteristics and, as a result, affected their stability and mobility in aquatic media (Chen et al. 2012; Loosli et al. 2013; Petosa et al. 2012). The enhancement of stability and mobility of $\mathrm{TiO}_{2} \mathrm{NPs}$ in these studies was attributable to the electrostatic and/or steric repulsive effects of adsorbed NOM. Humic substances (HS) with abundant carboxylic (- $\mathrm{COOH},-\mathrm{COO}-)$ and phenolic $(-\mathrm{OH})$ functional groups could exist as common negatively charged polyelectrolytes in aquatic environments (Jones and Su 2012). The presence of $\mathrm{HS}$ might inverse the positively charged $\mathrm{TiO}_{2} \mathrm{NPs}$ in acidic conditions, subsequently alter the favorable interaction between $\mathrm{TiO}_{2}$ NPs and collector, and facilitate the mobility of the nanoparticles, thereby increasing the risk of $\mathrm{TiO}_{2}$ NPs in acidic conditions.

The objective of this study was to investigate the influences of different environmentally relevant factors such as $\mathrm{HS}, \mathrm{pH}$, and ionic strength on the stability 
and transport behavior of $\mathrm{TiO}_{2} \mathrm{NPs}$ in saturated porous media under acidic conditions. Systematic aggregation and mobility experiments of $\mathrm{TiO}_{2} \mathrm{NPs}$, supplemented with necessary mechanisms governing the stability and transport, were performed. It was hoped that results of this study would provide insights into the potential fate and the subsequent risk of $\mathrm{TiO}_{2} \mathrm{NPs}$ in acidic environments.

\section{Materials and methods}

Characterization of the porous medium

Quartz sand (40-70 mesh) was obtained from Sinopharm Chemical Reagent Co., Ltd. The sand particles had an average diameter of approximately $350 \mu \mathrm{m}$. Surface impurities were removed by soaking in $12 \mathrm{~mol} \mathrm{~L}^{-1} \mathrm{HCl}$ for $24 \mathrm{~h}$ followed by rinsing with deionized water $(18.2 \mathrm{M} \Omega \mathrm{cm})$ until the $\mathrm{pH}$ of the rinse solution matched that of the deionized water. The media were then baked in a furnace (FB1400, Thermo Scientific) at $120{ }^{\circ} \mathrm{C}$ for $1 \mathrm{~h}$ and then at $800{ }^{\circ} \mathrm{C}$ for $5 \mathrm{~h}$ (Litton and Olson 1993).

\section{Preparation of $\mathrm{TiO}_{2}$ NPs suspensions}

The $\mathrm{TiO}_{2}$ NPs were obtained from Shanghai Aladdin Reagent Co., Ltd with a nominal size of $30 \pm 10 \mathrm{~nm}$ and were used as received in all experiments. The crystalline composition of the nanoparticles was determined to be a pure anatase phase by X-ray diffraction (XRD, Ultima IV, Rigaku, Japan) (Fig. $\mathrm{S} 1$ ). The specific surface area of the nanoparticles was measured to be $80.8 \mathrm{~m}^{2} \mathrm{~g}^{-1}$ in a multipoint mode using a TriStar II 3020 pore size and surface area analyzer. The PZC of $\mathrm{TiO}_{2} \mathrm{NPs}$ was determined to be 6.2 in deionized water (Fig. S2). Stocking suspension of $\mathrm{TiO}_{2}$ NPs was prepared by adding $250 \mathrm{mg}$ of nanoparticles to $1.0 \mathrm{~L}$ of deionized water. The suspension was sonicated for $30 \mathrm{~min}(500 \mathrm{~W}$, $40 \mathrm{kHz})$ at room temperature $\left(20^{\circ} \mathrm{C}\right)$ and stored no longer than 2 days at $4{ }^{\circ} \mathrm{C}$. Immediately prior to each experiment, an aqueous suspension containing a final $\mathrm{TiO}_{2}$ NPs concentration of $50 \mathrm{mg} \mathrm{L}^{-1}$ and the desired solution chemistry was produced by diluting the stocking suspension in background solution. A wide range of background solution chemistry was examined in experiments, namely HS concentrations of
0-10 mg L ${ }^{-1}, \mathrm{pH} 4.0-6.0, \mathrm{NaCl}$ concentrations of $0.1-250 \mathrm{mmol} \mathrm{L}^{-1}$, and $\mathrm{CaCl}_{2}$ concentrations of 0.5-5.0 mmol L ${ }^{-1}$ (Table S2). The humic substances (fulvic acid $\geq 90 \%$, reported by the vendor) were supplied by Shanghai Aladdin Reagent Co., Ltd. and were used as a model NOM. Zeta potential and particle size distribution of the prepared $\mathrm{TiO}_{2} \mathrm{NPs}$ suspensions were measured with Zetasizer Nano ZS90 (Malvern Instruments).

\section{Column experiments}

Glass columns $(2.5 \mathrm{~cm}$ in diameter and $10 \mathrm{~cm}$ in length) were packed uniformly with clean quartz sand. The resulting porosity of the porous medium was gravimetrically measured to be $0.42-0.47$. Once packed, the column was flushed with at least 10 pore volumes (PV) of background solution with the desired $\mathrm{HS}, \mathrm{pH}$, and ions as a pre-equilibration procedure. Then $2 \mathrm{PV}$ of $\mathrm{TiO}_{2} \mathrm{NPs}$ suspensions $\left(50 \mathrm{mg} \mathrm{L}^{-1}\right)$ with the same background chemistry were introduced into the column, followed by a nanoparticle-free background electrolyte solution. The Darcy velocity was maintained at $0.35-0.38 \mathrm{~cm} \mathrm{~min}^{-1}$ for all experiments. Column effluent was collected using a BS-110A fraction collector (Huxi Analytical Instrument Factory Co., Ltd., China). The concentrations of $\mathrm{TiO}_{2}$ NPs in the influent $\left(\mathrm{C}_{0}\right)$ and effluent $(C)$ were determined spectrophotometrically at a wavelength of $343 \mathrm{~nm}$. All transport experiments were conducted in duplicate with a deviation $<3 \%$, and therefore, only one representative breakthrough curve for each experiment was shown in the results.

\section{Results and discussion}

Electrokinetic and aggregation properties of $\mathrm{TiO}_{2}$ NPs in suspensions

The stability of nanoparticles in suspensions is a key factor affecting their transport and deposition behaviors in porous media (Espinasse et al. 2007). Experiments at $\mathrm{pH} 4.0$ were conducted to quantify the modification of the surface charge and aggregation behavior of $\mathrm{TiO}_{2} \mathrm{NPs}$ by HS coating. As illustrated in Fig. 1a, a positive zeta potential of $\mathrm{TiO}_{2}$ NPs was $+28.4 \mathrm{mV}$ in the absence of $\mathrm{HS}$ and declined to $-3.6 \mathrm{mV}$ at $0.5 \mathrm{mg} \mathrm{L}^{-1}$ of HS. A higher $\mathrm{HS}$ 
concentration of $10 \mathrm{mg} \mathrm{L}^{-1}$ further depressed the zeta potential to $-37.5 \mathrm{mV}$. As shown in Fig. S5, the amount of HS adsorbed onto $\mathrm{TiO}_{2}$ NPs increased gradually from $0.109 \mathrm{mg} \mathrm{m}^{-2}$ under an initial HS concentration of $0.5 \mathrm{mg} \mathrm{L}^{-1}-0.833 \mathrm{mg} \mathrm{m}^{-2}$ under an initial HS concentration of $10 \mathrm{mg} \mathrm{L}^{-1}$ at $\mathrm{pH} 4.0$. Adsorption of $0.109 \mathrm{mg} \mathrm{m}^{-2} \mathrm{HS}$ on surfaces inversed the positive potential of $\mathrm{TiO}_{2} \mathrm{NPs}$. The effect of $\mathrm{HS}$ on the zeta potential of $\mathrm{TiO}_{2}$ NPs could be attributed to the negative charge of HS adsorbed onto the surface of $\mathrm{TiO}_{2}$ NPs at the given pH (Fig. S2). Moreover, ligand exchange of hydroxyl groups on $\mathrm{TiO}_{2} \mathrm{NPs}$ surfaces with HS might diminish hydroxyl groups for protonation which could also be partly responsible for the decrease in the positive charge (Bian et al. 2011). Organic anions of HS (Table S1 and Fig. S4) could also increase the negative charge density adjacent to the particle surface and cause a shift in the position of the shear plane further away from the surface, and thus result in a decrease in zeta potential of $\mathrm{TiO}_{2} \mathrm{NPs}$ (Bian et al. 2011; Zhang et al. 2009). Because of the protonation of the surface groups of $\mathrm{TiO}_{2} \mathrm{NPs}$ and
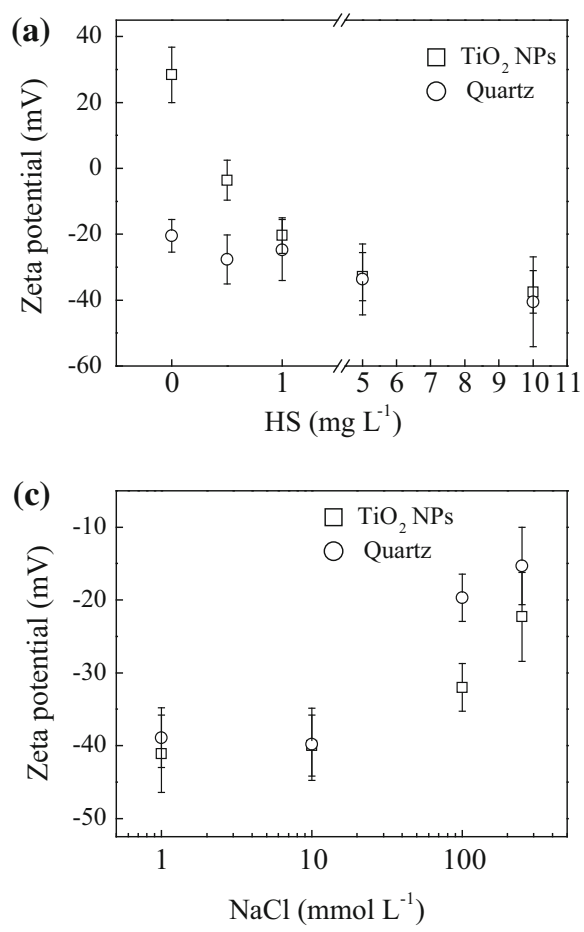

Fig. 1 Zeta potential of $\mathrm{TiO}_{2} \mathrm{NPs}$ and quartz as a function of HS concentration ( $\mathrm{pH} 4.0$ and $\left.0.1 \mathrm{mmol} \mathrm{L}^{-1} \mathrm{NaCl}\right)(\mathbf{a}), \mathrm{pH}$ $\left(5 \mathrm{mg} \mathrm{L}^{-1} \mathrm{HS}\right.$ and $\left.0.1 \mathrm{mmol} \mathrm{L}^{-1} \mathrm{NaCl}\right)(\mathbf{b}), \mathrm{NaCl}$ concentration adsorbed HS, the zeta potential of $\mathrm{TiO}_{2} \mathrm{NPs}$ became less negative with decreasing $\mathrm{pH}$ from 6.0 to 4.0 (Fig. 1b). As shown in Fig. 1c, the absolute magnitude of the zeta potential of $\mathrm{TiO}_{2} \mathrm{NPs}$ varied inversely with ionic strength in aqueous solution with $5 \mathrm{mg} \mathrm{L}^{-1} \mathrm{HS}$ at $\mathrm{pH}$ 5.0, due to the charge screen effect and electric double layer compression for all surfaces (Chen et al. 2012). In addition, binding of $\mathrm{Ca}^{2+}$ to the functional groups of HS coated on $\mathrm{TiO}_{2}$ NPs could lead to a decrease of negative charge other than charge screening (Amirbahman and Olson 1995; Xu et al. 2011). These two mechanisms could explain the greater influence of $\mathrm{CaCl}_{2}$ on the zeta potential of $\mathrm{TiO}_{2} \mathrm{NPs}$ than that of $\mathrm{NaCl}$ at the same ionic strength (Fig. 1d). Similar to previous reports (Chen et al. 2012), the surface of the quartz sand was negatively charged over the entire range of $\mathrm{HS}$ concentrations, $\mathrm{pH}$, and ionic strength conditions examined in this study (Fig. 1).

Table 1 shows that all the $\mathrm{TiO}_{2}$ NPs were present in aggregates larger than $400 \mathrm{~nm}$ rather than primary particles of $30 \mathrm{~nm}$. DLVO patterns in Figs. 2 and S7 could interpret the aggregation of $\mathrm{TiO}_{2}$ NPs. Net
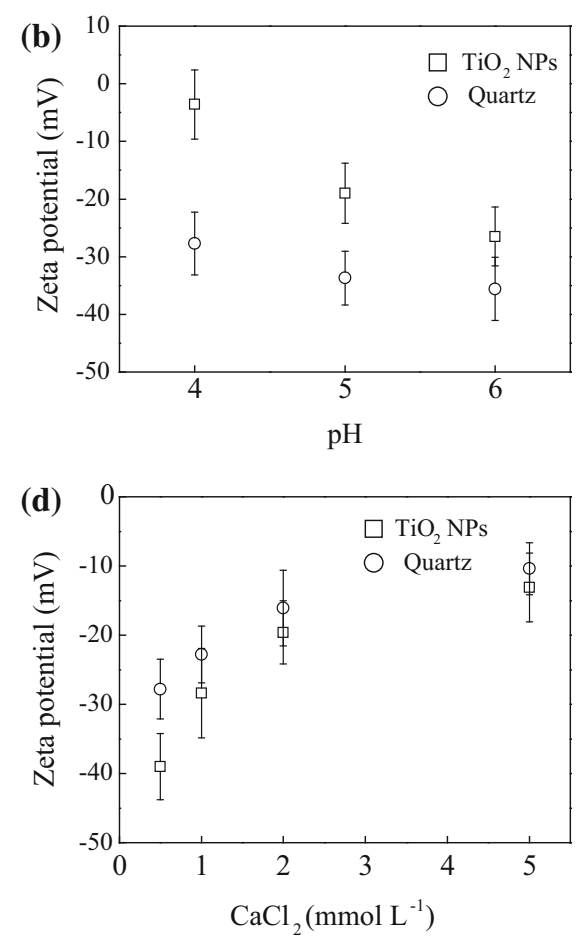

(pH 5.0 and $5 \mathrm{mg} \mathrm{L}^{-1} \mathrm{HS}$ ) (c), and $\mathrm{CaCl}_{2}$ concentration ( $\mathrm{pH} 5.0$ and $\left.5 \mathrm{mg} \mathrm{L}^{-1} \mathrm{HS}\right)(\mathbf{d})$ 


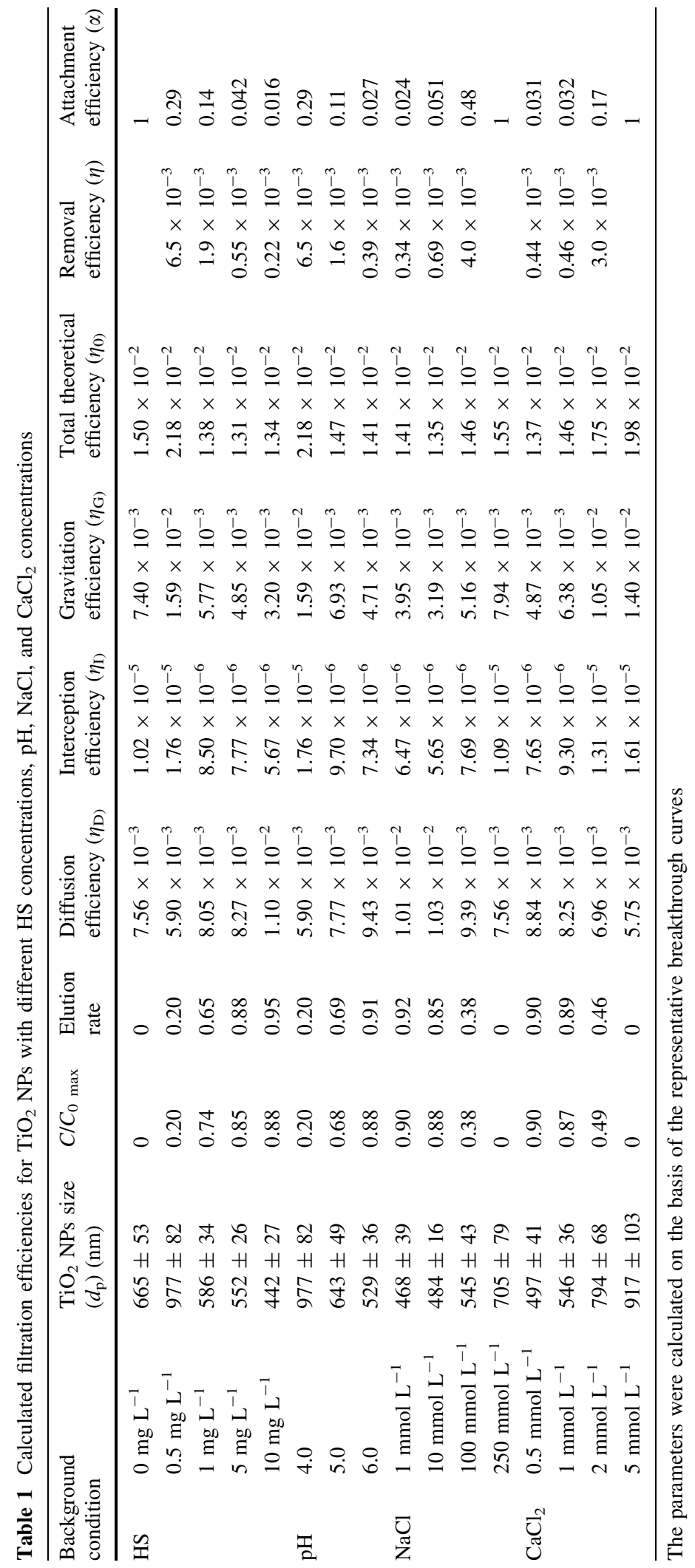



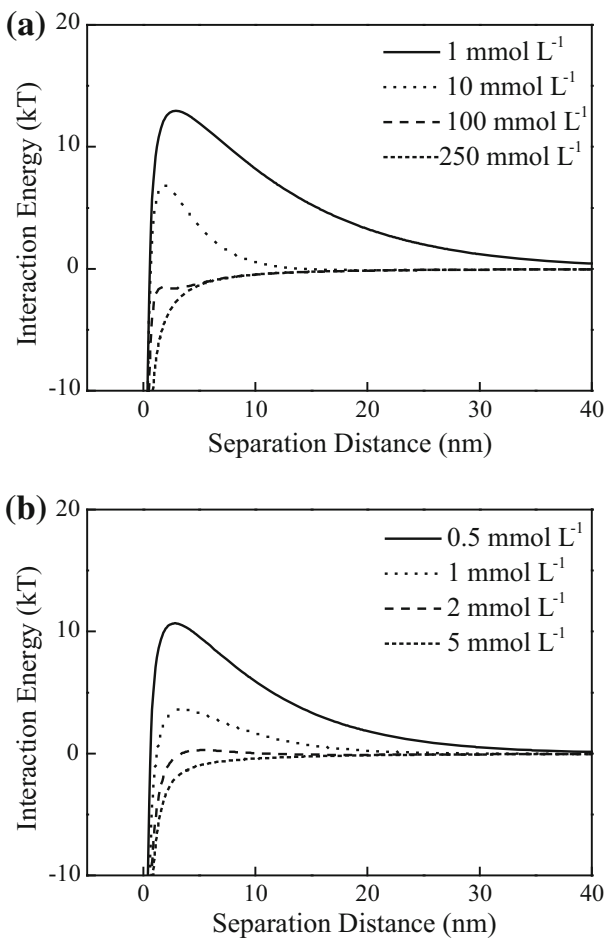

Fig. 2 Calculated DLVO interaction energy between $\mathrm{TiO}_{2} \mathrm{NPs}$ (based on primary size) under varying $\mathrm{NaCl}$ (a) and $\mathrm{CaCl}_{2}$ (b) concentration ( $\mathrm{pH} 5.0$ and $5 \mathrm{mg} \mathrm{L}^{-1} \mathrm{HS}$ )

repulsive energy barriers between $\mathrm{TiO}_{2}$ NPs in all cases were $<20 \mathrm{kT}$, the recognized limit for prevention of coagulation of particles after collision (Cosgrove 2005). Specially, electrostatically favorable conditions were observed in the background conditions of $\mathrm{pH} 4.0,250 \mathrm{mmol} \mathrm{L}^{-1} \mathrm{NaCl}$, and $5 \mathrm{~m}$ mol L ${ }^{-1} \mathrm{CaCl}_{2}$. Deep primary energy wells in these cases resulted in aggregates of $\mathrm{TiO}_{2}$ NPs larger than $700 \mathrm{~nm}$. The details of interaction energy calculation are provided in the supplementary material.

As noted in Fig. S7, $\mathrm{TiO}_{2}$ NPs had a net repulsive energy barrier in the absence of HS. With the addition of HS, the energy barrier decreased and approached zero at $0.5 \mathrm{mg} \mathrm{L}^{-1} \mathrm{HS}$, and this was observed visually by the greater size of $977 \mathrm{~nm}$ shown in Table 1 . However, the net repulsive energy barrier began to increase with further addition of HS, a finding consistent with the decreasing of $\mathrm{TiO}_{2}$ NPs aggregate size. Additionally, decreasing $\mathrm{pH}$ or elevating ionic strength resulted in reduction of the net repulsive barrier and then led to $\mathrm{TiO}_{2}$ NPs aggregate of larger size. The diverse electrokinetic properties and aggregation of $\mathrm{TiO}_{2}$ NPs would lead to a variety of mobility behaviors in porous media.

Transport of $\mathrm{TiO}_{2}$ NPs in porous media under acidic conditions

The transport breakthrough curves of $\mathrm{TiO}_{2}$ NPs were obtained for a wide range of solution chemistry, i.e., HS 0-10 mg L ${ }^{-1}$, pH 4.0-6.0, $\mathrm{NaCl} 1-250 \mathrm{mmol} \mathrm{L}^{-1}$, and $\mathrm{CaCl}_{2}$ 0.5-5 mmol L ${ }^{-1}$. Representative results of breakthrough curves are presented in Fig. 3 and Table 1. Pulse injection of $\mathrm{TiO}_{2}$ NPs into columns yielded asymmetrical breakthrough curves that gradually rose to a maximum value before declining sharply to a relative concentration $\left(C / C_{0}\right)$ approaching zero. Due to the opposite surface charges of quartz and nanoparticles, $\mathrm{TiO}_{2} \mathrm{NPs}$ were almost immobile in the absence of HS at the acidic pH tested (Fig. 3a, Fig. S9). Negative charge of both quartz sand and $\mathrm{TiO}_{2}$ NPs resulting from the coating of HS on the surface indicated that the existence of electrostatic repulsive forces led to unfavorable conditions for deposition of $\mathrm{TiO}_{2}$ NPs onto the collector (Chowdhury et al. 2011). The elution of $\mathrm{TiO}_{2}$ NPs from the columns was dramatically enhanced with increase of HS, and the maximum $C / C_{0}$ observed increased from 0.20 to 0.88 with a change in HS concentration from $0.5 \mathrm{mg} \mathrm{L}^{-1}$ to $10 \mathrm{mg} \mathrm{L}^{-1}$ (Table 1). As noted from breakthrough curves of $\mathrm{TiO}_{2}$ NPs with suspensions $\mathrm{pH}$ of 4.0, 5.0 and 6.0 (Fig. 3b), the $\mathrm{pH}$ was found to have significant effects on the transport of $\mathrm{TiO}_{2} \mathrm{NPs}$. Increasing of $\mathrm{Cl}$ $C_{0 \text { max }}$ (Table 1) suggested that elevating $\mathrm{pH}$ from 4.0 to 6.0 facilitated the transport of $\mathrm{TiO}_{2} \mathrm{NPs}$ in the quartz sand columns. Results presented in Fig. 3c, d show the effect of $\mathrm{NaCl}$ and $\mathrm{CaCl}_{2}$ on the mobility of $\mathrm{TiO}_{2} \mathrm{NPs}$ in porous media and almost similar transport behavior was observed with $\mathrm{NaCl}$ and $\mathrm{CaCl}_{2}$ concentration $<10$ and $<1 \mathrm{mmol} \mathrm{L}^{-1}$, respectively. This suggested that the mobility of $\mathrm{TiO}_{2}$ NPs was insensitive to low solution ionic strengths. However, the clear reduction of $C / C_{0}$ max demonstrated that mobility was observed at higher electrolyte concentrations, and this was consistent with the decrease of zeta potentials presented in Fig. 1. Furthermore, high ionic strengths such as $250 \mathrm{mmol} \mathrm{L}^{-1} \mathrm{NaCl}$ or $5 \mathrm{mmol} \mathrm{L}^{-1} \mathrm{CaCl}_{2}$ led to deposition of all the $\mathrm{TiO}_{2}$ NPs onto the porous media.

It is worth noting that NOM concentrations of groundwater and surface waters often fall in the ranges 
from 0.25 to 5 and $2.5-50 \mathrm{mg} \mathrm{L}^{-1}$, and can be up to around $2 \mathrm{~g} \mathrm{~L}^{-1}$ in wastewaters (Chen et al. 2012; Crittenden and Montgomery Watson Harza (Firm) 2005). Moreover, in ground water the concentrations of monovalent cations (e.g. $\mathrm{Na}^{+}, \mathrm{K}^{+}$) are typically 1-10 $\mathrm{mmol} \mathrm{L}^{-1}$ and of divalent cations (e.g., $\mathrm{Ca}^{2+}$, $\mathrm{Mg}^{2+}$ ) are typically $0.1-2 \mathrm{mmol} \mathrm{L}^{-1}$ (Saleh et al. 2008). Therefore, according to results of the present study, it is reasonable to infer that $\mathrm{TiO}_{2}$ NPs could be very stable and mobile in certain acidic surface waters and groundwater due to the abundance of NOM and relatively low ionic strength.

Mechanisms governing the transport of $\mathrm{TiO}_{2} \mathrm{NPs}$

\section{Interpretation with DLVO theory}

Energy profiles for interactions between $\mathrm{TiO}_{2} \mathrm{NPs}$ and quartz sand across a range of solution conditions are presented in Figs. 4 and S9. High energy barrier (180-500 kT) existed between $\mathrm{TiO}_{2}$ NPs and quartz sand with HS concentration $>1 \mathrm{mg} \mathrm{L}^{-1}$ (Fig. S10a), suggesting unfavorable conditions for $\mathrm{TiO}_{2}$ NPs retention in quartz sand columns. However, a substantial deep primary energy well $(<-500 \mathrm{kT})$ occurred when HS concentration was $<1 \mathrm{mg} \mathrm{L}^{-1}$, indicating favorable conditions for $\mathrm{TiO}_{2}$ NPs deposition onto quartz surfaces. The calculated interaction energy profiles were consistent with the observed mobility trends of $\mathrm{TiO}_{2}$ NPs under different HS concentrations in the porous media columns. As indicated in previous studies, $\mathrm{pH}$ was another factor influencing the DLVO interaction energy (Fang et al. 2013). Higher $\mathrm{pH}$ (5.0 and 6.0) resulted in significant elution in column experiments due to high energy barrier (220-310 kT), whereas an electrostatically favorable condition observed at $\mathrm{pH} 4.0$ induced marked retention of $\mathrm{TiO}_{2}$ NPs in quartz (Fig. S10b).

According to electric double layer and DLVO theory, the higher the ionic strength, the lower the elution will be due to a low energy barrier and greater tendency for nanoparticle aggregation (He et al. 2008; Rahman et al. 2013). No energy barrier and deep primary energy well $(<-800 \mathrm{kT})$ in DLVO profiles indicated completely favorable conditions for deposition of $\mathrm{TiO}_{2} \mathrm{NPs}$ onto surfaces of quartz in columns at $100 \mathrm{mmol} \mathrm{L}{ }^{-1} \mathrm{NaCl}$ (Fig. 4a) and $5 \mathrm{mmol} \mathrm{L}^{-1} \mathrm{CaCl}_{2}$ (Fig. 4b). Although a high energy barrier (34 kT) was observed for $100 \mathrm{mmol} \mathrm{L}^{-1} \mathrm{NaCl}$, the presence of the deep secondary energy well $(-11 \mathrm{kT})$ could capture
Fig. 3 Breakthrough curves for $\mathrm{TiO}_{2} \mathrm{NPs}$ at different HS concentrations (a), $\mathrm{pH}(\mathbf{b}), \mathrm{NaCl}$ concentrations (c), and $\mathrm{CaCl}_{2}$ concentrations $(\mathbf{d})$
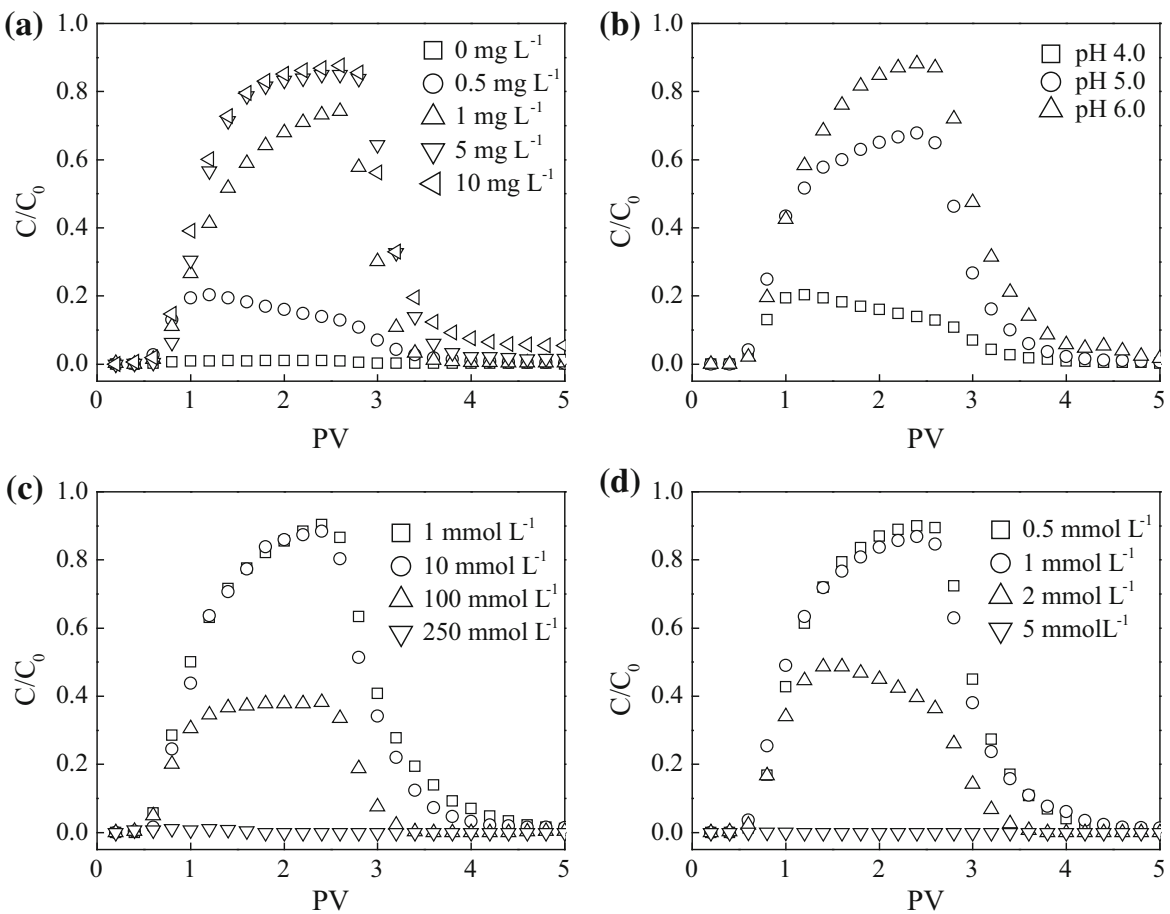
Fig. 4 Calculated DLVO interaction energy between $\mathrm{TiO}_{2}$ NPs (based on aggregated size) and quartz sand under varying $\mathrm{NaCl}$ (a, c) and $\mathrm{CaCl}_{2}(\mathbf{b}$,

d) concentration ( $\mathrm{pH} 5.0$ and $5 \mathrm{mg} \mathrm{L}^{-1} \mathrm{HS}$ )
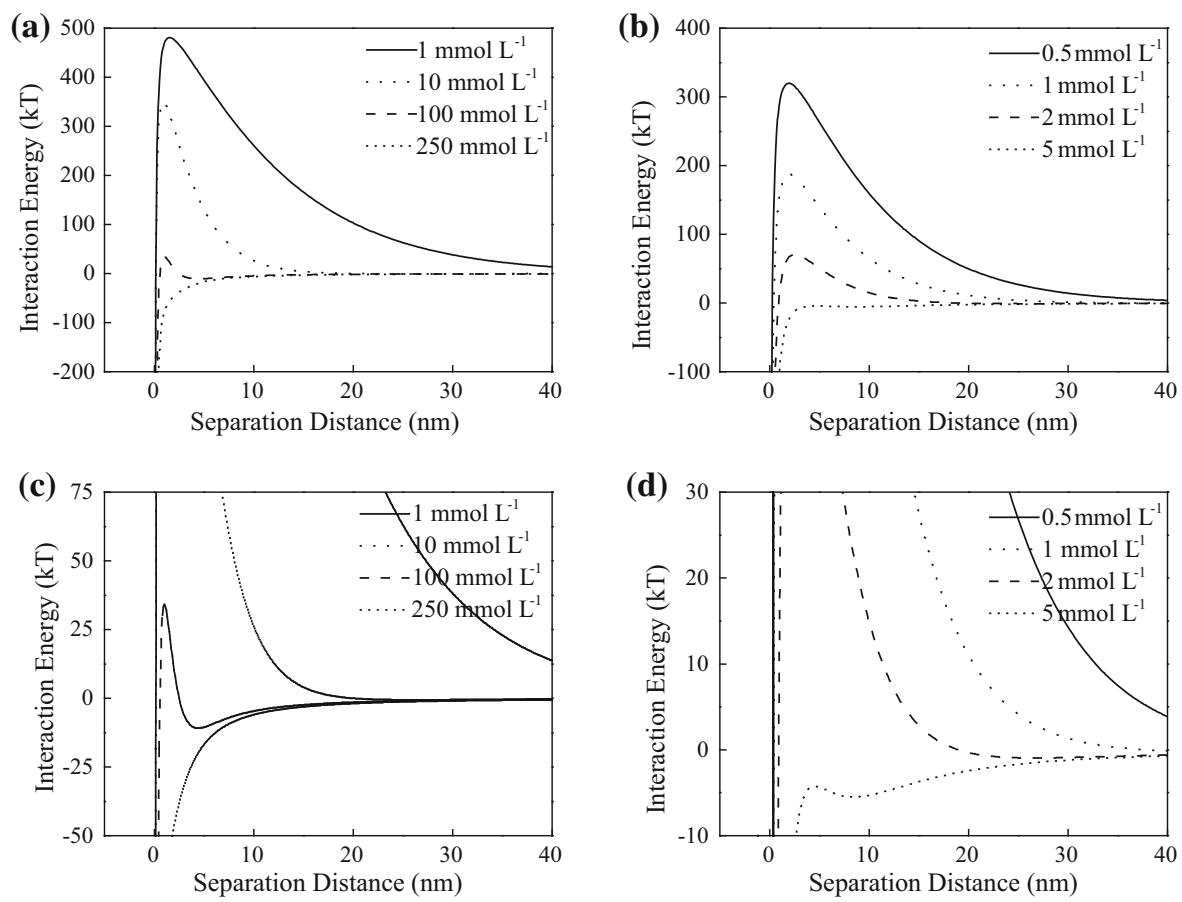

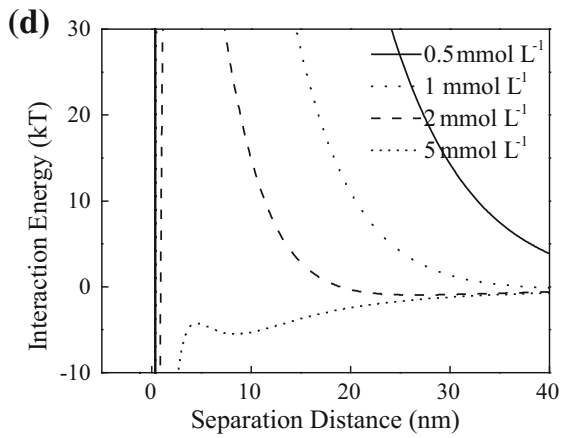

substantial $\mathrm{TiO}_{2}$ NPs unless they had sufficient kinetic energy to escape back into solution. Given this, $72 \%$ of $\mathrm{TiO}_{2}$ NPs in the influent deposited in the column.

Surprisingly, a high energy barrier for $2 \mathrm{mmol} \mathrm{L}^{-1}$ $\mathrm{CaCl}_{2}(70 \mathrm{kT})$, as well as for $\mathrm{pH} 5.0(220 \mathrm{kT})$ and $1 \mathrm{mg} \mathrm{L}^{-1} \mathrm{HS}(180 \mathrm{kT})$, did not prevent $\mathrm{TiO}_{2} \mathrm{NPs}$ from depositing onto surfaces of quartz as anticipated. Hence, some of the observed transport trends were inconsistent with the DLVO predictions, and this might be explained by aggregation and subsequent straining (Chowdhury et al. 2011; Rahman et al. 2013; Solovitch et al. 2010).

\section{Contribution of $\mathrm{TiO}_{2} \mathrm{NPs}$ aggregation and straining}

DLVO theory predicts only particle-particle and particle-collector interactions, but it is insufficient for the description of physicochemical processes including straining, ripening, and blocking (Chowdhury et al. 2011; Elimelech 1995). Blocking is referred to as a continuous decrease of the rate of particle deposition due to the non-availability of attachment sites on the surface of the collector grains (Song and Elimelech 1993). The phenomenon is most important under conditions of favorable particle-collector interaction and unfavorable particle-particle interaction (Chowdhury et al. 2011; Song and Elimelech 1993). However, since favorable particle-collector interaction and unfavorable particle-particle interaction did not occur simultaneously, blocking might not have occurred in this study. The aggregation of $\mathrm{TiO}_{2} \mathrm{NPs}$, common in all tested conditions, and subsequent straining might contribute to the retention of particles in packed columns with background solution of $2 \mathrm{mmol} \mathrm{L}^{-1} \mathrm{CaCl}_{2}$, pH 5.0, and $1 \mathrm{mg} \mathrm{L}^{-1} \mathrm{HS}$, in spite of the presence of energy barriers $>70 \mathrm{kT}$.

Straining is the trapping of colloid particles in the downgradient pore throats that are too small to allow particle passage (Mcdowellboyer et al. 1986). In principle, straining is controlled by the size of the nanoparticles and the pore size distribution characteristics of porous media. Empirically, straining has been considered to be an important particle retention mechanism when the ratio of the colloid diameter to the mean gain diameter is greater than 0.0017 (Bradford et al. 2002; Chen et al. 2012). Since the average size of quartz packed in columns in this study was $350 \mu \mathrm{m}$, the threshold of nanoparticle aggregates size for straining would be $595 \mathrm{~nm}$. Due to insufficient repulsive energy between $\mathrm{TiO}_{2}$ NPs, the size of 
aggregates reached to 586, 643, 794 and $917 \mathrm{~nm}$ in background solution with $1 \mathrm{mg} \mathrm{L}^{-1} \mathrm{HS}$, pH 5.0, $2 \mathrm{mmol} \mathrm{L}^{-1} \mathrm{CaCl}_{2}$, and $0.5 \mathrm{mg} \mathrm{L}^{-1} \mathrm{HS}$, respectively. It is considerably inferred that straining under the latter three conditions would result in the significant retention of $\mathrm{TiO}_{2}$ NPs in transport experiments. It is worth noting that, in hydrodynamic measurements, the size of aggregates in suspension at $1 \mathrm{mg} \mathrm{L}^{-1} \mathrm{HS}$ was widely distributed (Fig. S11), and $>30 \%$ of aggregates exceeded the critical size of $595 \mathrm{~nm}$. As a result, straining was inevitably involved in the retention of $\mathrm{TiO}_{2}$ NPs under this condition. Although straining did not necessarily lead to ripening, the ripening-shape breakthrough curve in the study was obtained at $2 \mathrm{mmol} \mathrm{L}^{-1} \quad \mathrm{CaCl}_{2}$ and $0.5 \mathrm{mg} \mathrm{L}^{-1} \mathrm{HS}$ (Fig. 3), which illustrated the greater $\mathrm{TiO}_{2}$ NPs mass transfer to collector surfaces. As shown in Fig. 5, no energy barrier existed between $\mathrm{TiO}_{2} \mathrm{NPs}$, and a deeper energy well in the DLVO profile was calculated between $\mathrm{TiO}_{2}$ NPs than that between $\mathrm{TiO}_{2}$ NPs and quartz, which together could lead to more favorable interaction for attachment between approaching $\mathrm{TiO}_{2} \mathrm{NPs}$ and $\mathrm{TiO}_{2}$ NPs that had already been deposited on the collector (Chen et al. 2011, 2012). Deposition of $\mathrm{TiO}_{2}$ NPs was then enhanced, whereas it might be another factor responsible for the ripening phenomenon at $0.5 \mathrm{mg} \mathrm{L}^{-1} \mathrm{HS}$, that is, the larger $\mathrm{TiO}_{2}$ NPs aggregates in this scenario blocked the path of the pores (Lu et al. 2013).

\section{Physical filtration effect}

Classic filtration theory is used to explain the mechanism for deposition of colloidal particles on

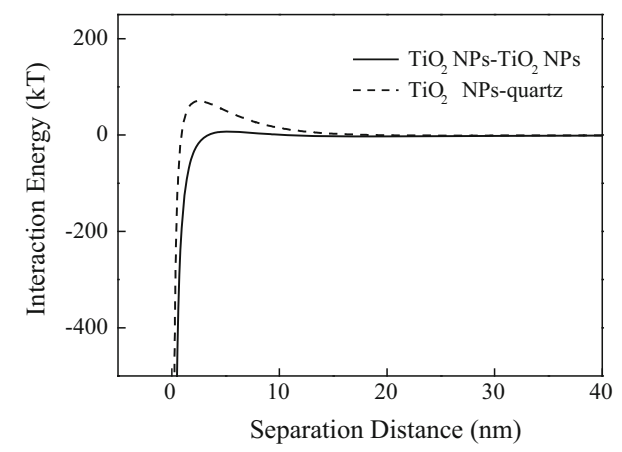

Fig. 5 Calculated DLVO interaction energy between $\mathrm{TiO}_{2} \mathrm{NPs}$ (based on aggregated size) and between $\mathrm{TiO}_{2}$ NPs (based on aggregated size) and quartz sand at $2 \mathrm{mmol} \mathrm{L}^{-1} \mathrm{CaCl}_{2}$ porous media (Rahman et al. 2013; Tufenkji and Elimelech 2004; Yao et al. 1971). Particles suspended in pore fluid contact porous media surfaces through three mechanisms: diffusion, interception, and gravitational sedimentation. The efficiency of diffusion, interception, and gravitational sedimentation calculated for each background condition as provided in the supplementary material are listed in Table 1 . In general, attachment efficiency $(\alpha)$ decreased with increasing of $\mathrm{HS}$ concentration and $\mathrm{pH}$, and increased with increasing $\mathrm{NaCl}$ and $\mathrm{CaCl}_{2}$ concentrations, which compared well with the elution rates in transport experiments. Values of $\alpha<1$ were consistent with the significant mobility of $\mathrm{TiO}_{2} \mathrm{NPs}$ from porous media observed in experiments.

Diffusion efficiency $\left(\eta_{\mathrm{D}}\right)$ comprised $27-82 \%$ of total filtration efficiency $\left(\eta_{0}\right)$ under various conditions. It varied inversely with $\mathrm{TiO}_{2} \mathrm{NPs}$ size in the influent, which increased from $5.90 \times 10^{-3}$ for $0.5 \mathrm{mg} \mathrm{L}^{-1} \mathrm{HS}$ $\left(\mathrm{TiO}_{2}\right.$ NPs size of $\left.977 \mathrm{~nm}\right)$ to $1.10 \times 10^{-2}$ for $10 \mathrm{mg}$ $\mathrm{L}^{-1} \mathrm{HS}\left(\mathrm{TiO}_{2} \mathrm{NPs}\right.$ size of $\left.442 \mathrm{~nm}\right)$. Numerous previous studies have reported diffusion as the predominant mechanism for deposition of nanoparticles $<100 \mathrm{~nm}$ in porous media (He et al. 2009; Rahman et al. 2013; Zhuang et al. 2005). Due to the large aggregate size of $\mathrm{TiO}_{2}$ NPs, gravitational sedimentation played an important role in this study. Contrary to $\eta_{\mathrm{D}}$, gravitational efficiency $\left(\eta_{\mathrm{G}}\right)$ varied in the same direction as $\mathrm{TiO}_{2}$ NPs size. Taking a batch of $\mathrm{CaCl}_{2}$ as an example, $\eta_{\mathrm{G}}$ increased about three times for $\mathrm{TiO}_{2} \mathrm{NPs}$ in $5 \mathrm{mmol} \mathrm{\textrm {L } ^ { - 1 }} \mathrm{CaCl}_{2}(977 \mathrm{~nm})$, compared with $\mathrm{TiO}_{2} \mathrm{NPs}$ in $0.5 \mathrm{mmol} \mathrm{L}{ }^{-1} \mathrm{CaCl}_{2}$ $(546 \mathrm{~nm})$. Interception efficiency $\left(\eta_{\mathrm{I}}\right)$ was negligible relative to $\eta_{\mathrm{D}}$ and $\eta_{\mathrm{G}}$, which comprised $<1 \%$ of total filtration efficiency $\left(\eta_{0}\right)$ under various conditions. To sum up, diffusion was suggested to be a major mechanism for deposition of smaller $\mathrm{TiO}_{2} \mathrm{NPs}$, while larger particles were retained primarily due to gravitational sedimentation.

\section{Conclusions}

The stability and transport behaviors of $\mathrm{TiO}_{2}$ NPs in porous media columns packed with clean quartz were investigated in various background solutions under acidic conditions in the present study. Solution chemistry was found to have a remarkable effect on the electrokinetic properties and stability of $\mathrm{TiO}_{2} \mathrm{NPs}$ 
and as a result on the mobility in the porous media. Due to the favorable interactions between $\mathrm{TiO}_{2} \mathrm{NPs}$ and the collector, $\mathrm{TiO}_{2} \mathrm{NPs}$ were immobile in the porous media at $\mathrm{pH} 4.0-6.0$ in the absence of HS. Humic substances present in background solution were readily adsorbed onto the $\mathrm{TiO}_{2}$ NPs surfaces and the adsorbed $\mathrm{HS}$ altered the electrokinetic properties of the $\mathrm{TiO}_{2}$ NPs and quartz, and this drastically enhanced the stability and mobility of the $\mathrm{TiO}_{2} \mathrm{NPs}$. Enhancement of mobility was also observed when the $\mathrm{pH}$ was elevated from 4.0 to 6.0. Although low ionic strength was unfavorable for $\mathrm{TiO}_{2} \mathrm{NPs}$ deposition and resulted in its high mobility in porous media, electrolyte concentrations $>100 \mathrm{mmol} \mathrm{L}^{-1} \mathrm{NaCl}$ or $>2 \mathrm{mmol} \mathrm{L}^{-1} \mathrm{CaCl}_{2}$ significantly inhibited the mobility. DLVO theory together with straining and physical filtration effects could interpret the transport and retention of $\mathrm{TiO}_{2} \mathrm{NPs}$ in porous media well. High energy barriers facilitated the transport of $\mathrm{TiO}_{2} \mathrm{NPs}$. However, the presence of secondary energy well, straining, and gravitational settlement of larger aggregates was the predominant mechanisms of deposition of $\mathrm{TiO}_{2}$ NPs onto collector surfaces. This study suggested that in most acidic aquatic environment, NOM ubiquitously existing in natural waters could facilitate the mobility of $\mathrm{TiO}_{2}$ NPs even in the presence of moderate ionic strength. The risk assessment of $\mathrm{TiO}_{2} \mathrm{NPs}$ in aquatic systems requires further study due to their high mobility.

Acknowledgments This work was supported by the National Natural Science Foundation of China (41171248, 41230858).

Conflict of interest The authors declare that they have no conflict of interest.

\section{References}

Amirbahman A, Olson TM (1995) Deposition kinetics of humic matter-coated hematite in porous-media in the presence of $\mathrm{Ca}^{2+}$. Colloid Surf A 99:1-10. doi:10.1016/0927-7757(95) 03134-Y

Bian SW, Mudunkotuwa IA, Rupasinghe T, Grassian VH (2011) Aggregation and dissolution of $4 \mathrm{~nm} \mathrm{ZnO}$ nanoparticles in aqueous environments: influence of $\mathrm{pH}$, ionic strength, size, and adsorption of humic acid. Langmuir 27:6059-6068. doi:10.1021/La200570n

Bouchard D, Zhang W, Chang XJ (2013) A rapid screening technique for estimating nanoparticle transport in porous media. Water Res 47:4086-4094. doi:10.1016/j.watres. 2012.10.026
Bradford SA, Yates SR, Bettahar M, Simunek J (2002) Physical factors affecting the transport and fate of colloids in saturated porous media. Water Resour Res 38: 63-1-63-12 doi: 10.1029/2002wr001340

Chen X, Mao SS (2007) Titanium dioxide nanomaterials: synthesis, properties, modifications, and applications. Chem Rev 107:2891-2959. doi:10.1021/Cr0500535

Chen GX, Liu XY, Su CM (2011) Transport and retention of $\mathrm{TiO}_{2}$ rutile nanoparticles in saturated porous media under low-ionic-strength conditions: measurements and mechanisms. Langmuir 27:5393-5402. doi:10.1021/La200 $251 \mathrm{v}$

Chen GX, Liu XY, Su CM (2012) Distinct effects of humic acid on transport and retention of $\mathrm{TiO}_{2}$ rutile nanoparticles in saturated sand columns. Environ Sci Technol 46:71427150. doi:10.1021/Es204010g

Chowdhury I, Hong Y, Honda RJ, Walker SL (2011) Mechanisms of $\mathrm{TiO}_{2}$ nanoparticle transport in porous media: role of solution chemistry, nanoparticle concentration, and flowrate. J Colloid Interf Sci 360:548-555. doi:10.1016/j. jcis.2011.04.111

Cosgrove T (2005) Colloid science: principles, methods and applications. Blackwell Publishing, Oxford

Crittenden JC, Montgomery Watson Harza (Firm) (2005) Water treatment principles and design, 2nd edn. J. Wiley, Hoboken

Dietrich LAS, Sahu M, Biswas P, Fein JB (2012) Experimental study of $\mathrm{TiO}_{2}$ nanoparticle adhesion to silica and $\mathrm{Fe}$ (III) oxide-coated silica surfaces. Chem Geol 332:148-156. doi:10.1016/j.chemgeo.2012.09.043

Du WC, Sun YY, Ji R, Zhu JG, Wu JC, Guo HY (2011) $\mathrm{TiO}_{2}$ and $\mathrm{ZnO}$ nanoparticles negatively affect wheat growth and soil enzyme activities in agricultural soil. J Environ Monitor 13:822-828. doi:10.1039/C0em00611d

Elimelech M (1995) Particle deposition and aggregation: measurement, modelling, and simulation. Colloid and surface engineering series. Butterworth-Heinemann, Oxford

Espinasse B, Hotze EM, Wiesner MR (2007) Transport and retention of colloidal aggregates of C-60 in porous media: effects of organic macromolecules, ionic composition, and preparation method. Environ Sci Technol 41:7396-7402. doi:10.1021/Es0708767

Fang J, Shan XQ, Wen B, Lin JM, Owens G, Zhou SR (2011) Transport of copper as affected by titania nanoparticles in soil columns. Environ Pollut 159:1248-1256. doi:10.1016/ j.envpol.2011.01.039

Fang J, Xu MJ, Wang DJ, Wen B, Han JY (2013) Modeling the transport of $\mathrm{TiO}_{2}$ nanoparticle aggregates in saturated and unsaturated granular media: effects of ionic strength and pH. Water Res 47:1399-1408. doi:10.1016/j.watres.2012. 12.005

Ge YG, Schimel JP, Holden PA (2011) Evidence for negative effects of $\mathrm{TiO}_{2}$ and $\mathrm{ZnO}$ nanoparticles on soil bacterial communities. Environ Sci Technol 45:1659-1664. doi:10. 1021/Es103040t

Godinez IG, Darnault CJG (2011) Aggregation and transport of nano- $\mathrm{TiO}_{2}$ in saturated porous media: effects of $\mathrm{pH}$, surfactants and flow velocity. Water Res 45:839-851. doi:10. 1016/j.watres.2010.09.013

Gottschalk F, Sonderer T, Scholz RW, Nowack B (2009) Modeled environmental concentrations of engineered 
nanomaterials $\left(\mathrm{TiO}_{2}, \mathrm{ZnO}, \mathrm{Ag}, \mathrm{CNT}\right.$, fullerenes) for different regions. Environ Sci Technol 43:9216-9222. doi:10. 1021/Es9015553

He YT, Wan JM, Tokunaga T (2008) Kinetic stability of hematite nanoparticles: the effect of particle sizes. J Nanopart Res 10:321-332. doi:10.1007/s11051-007-9255-1

He F, Zhang M, Qian TW, Zhao DY (2009) Transport of carboxymethyl cellulose stabilized iron nanoparticles in porous media: column experiments and modeling. J Colloid Interface Sci 334:96-102. doi:10.1016/j.jcis.2009.02.058

Jones EH, Su CM (2012) Fate and transport of elemental copper $(\mathrm{Cu}-0)$ nanoparticles through saturated porous media in the presence of organic materials. Water Res 46:2445-2456. doi:10.1016/j.watres.2012.02.022

Keller AA, McFerran S, Lazareva A, Suh S (2013) Global life cycle releases of engineered nanomaterials. J Nanopart Res 15:1-17. doi:10.1007/S11051-013-1692-4

Lin DH, Tian XL, Wu FC, Xing BS (2010) Fate and transport of engineered nanomaterials in the environment. J Environ Qual 39:1896-1908. doi:10.2134/Jeq2009.0423

Litton GM, Olson TM (1993) Colloid Deposition rates on silica bed media and artifacts related to collector surface preparation methods. Environ Sci Technol 27:185-193. doi:10. 1021/Es00038a022

Loosli F, Le Coustumer P, Stoll S (2013) $\mathrm{TiO}_{2}$ nanoparticles aggregation and disaggregation in presence of alginate and Suwannee River humic acids. $\mathrm{pH}$ and concentration effects on nanoparticle stability. Water Res 47:6052-6063. doi:10. 1016/j.watres.2013.07.021

Lu YY, Xu XP, Yang K, Lin DH (2013) The effects of surfactants and solution chemistry on the transport of multiwalled carbon nanotubes in quartz sand-packed columns. Environ Pollut 182:269-277. doi:10.1016/j.envpol.2013.07.034

Mcdowellboyer LM, Hunt JR, Sitar N (1986) Particle-transport through porous-media. Water Resour Res 22:1901-1921. doi:10.1029/Wr022i013p01901

Menard A, Drobne D, Jemec A (2011) Ecotoxicity of nanosized $\mathrm{TiO}_{2}$. Review of in vivo data. Environ Pollut 159:677-684. doi:10.1016/j.envpol.2010.11.027

Petosa AR, Brennan SJ, Rajput F, Tufenkji N (2012) Transport of two metal oxide nanoparticles in saturated granular porous media: role of water chemistry and particle coating. Water Res 46:1273-1285. doi:10.1016/j.watres.2011.12. 033

Rahman T, George J, Shipley HJ (2013) Transport of aluminum oxide nanoparticles in saturated sand: effects of ionic strength, flow rate, and nanoparticle concentration. Sci Total Environ 463:565-571. doi:10.1016/j.scitotenv.2013. 06.049
Saleh N, Kim HJ, Phenrat T, Matyjaszewski K, Tilton RD, Lowry GV (2008) Ionic strength and composition affect the mobility of surface-modified $\mathrm{Fe}-0$ nanoparticles in water-saturated sand columns. Environ Sci Technol 42:3349-3355. doi:10.1021/Es071936b

Shih YH, Liu WS, Su YF (2012) Aggregation of stabilized $\mathrm{TiO}_{2}$ nanoparticle suspensions in the presence of inorganic ions. Environ Toxicol Chem 31:1693-1698. doi:10.1002/Etc. 1898

Solovitch N, Labille J, Rose J, Chaurand P, Borschneck D, Wiesner MR, Bottero JY (2010) Concurrent aggregation and deposition of $\mathrm{TiO}_{2}$ nanoparticles in a sandy porous media. Environ Sci Technol 44:4897-4902. doi:10.1021/ Es1000819

Song L, Elimelech M (1993) Dynamics of colloid deposition in porous media: modeling the role of retained particles. Colloid Surf A 73:49-63. doi:10.1016/0927-7757(93)80006-Z

Tufenkji N, Elimelech M (2004) Correlation equation for predicting single-collector efficiency in physicochemical filtration in saturated porous media. Environ Sci Technol 38:529-536. doi:10.1021/Es034049r

Wang Y et al (2012) Transport of titanium dioxide nanoparticles in saturated porous media under various solution chemistry conditions. J Nanopart Res 14:1095. doi:10.1007/S11051012-1095-Y

Xu YL, Qin Y, Palchoudhury S, Bao YP (2011) Water-soluble iron oxide nanoparticles with high stability and selective surface functionality. Langmuir 27:8990-8997. doi:10. 1021/La201652h

Yang WW et al (2014) $\mathrm{TiO}_{2}$ nanoparticles act as a carrier of $\mathrm{Cd}$ bioaccumulation in the ciliate Tetrahymena thermophila. Environ Sci Technol 48:7568-7575. doi:10.1021/Es500694t

Yao KM, Habibian MM, Omelia CR (1971) Water and waste water filtration: concepts and applications. Environ Sci Technol 5:1105-1112. doi:10.1021/Es60058a005

Zhang Y, Chen YS, Westerhoff P, Crittenden J (2009) Impact of natural organic matter and divalent cations on the stability of aqueous nanoparticles. Water Res 43:4249-4257. doi:10.1016/j.watres.2009.06.005

Zhou DM, Wang DJ, Cang L, Hao XZ, Chu LY (2011) Transport and re-entrainment of soil colloids in saturated packed column: effects of $\mathrm{pH}$ and ionic strength. J Soil Sediment 11:491-503. doi:10.1007/s11368-010-0331-2

Zhuang J, Qi J, Jin Y (2005) Retention and transport of amphiphilic colloids under unsaturated flow conditions: effect of particle size and surface property. Environ Sci Technol 39:7853-7859. doi:10.1021/Es050265j 